\title{
Kinerja Karyawan: Peran Transformasional SERAMBI Leadership dan Skill Competence
}

\author{
Nur Hikmah \\ Program Studi Administrasi Bisnis Internasi onal, Politeknik \\ Bal ekambang
}

\begin{abstract}
Purpose-The aim of this study is to estimate the effect of Transformational Leadership and Expertise Competencies on the employee performance of PBM TI Jepara. M ethods- D ata were collected through a questionnaire and then analyzed using SmartPLS (Partial Least Square). Finding- The results of the analysis show that transformational leadership and skills competencies influence performance. Unexpectedly, the results show that transformational leadership has a negative effect on performance, while the Skills Competency has a positive effect on performance.
\end{abstract}

\begin{abstract}
Abstrak
Tujuan- penelitian ini bertujuan mengestimasi pengaruh Kepemimpinan Transformasional dan Kompetensi Keahlian terhadap kinerja karyawan PBMTI Jepara. Metode: Data dikumpulkan melalui kuesioner dan kemudian dianalisis dengan menggunakan SmartPLS (Partial Least Square). Temuan: Hasil analisis menunjukkan bahwa kepemimpinan transformasional dan kompetensi keterampilan memiliki pengaruh terhadap kinerja. Diluar dugaan, hasil menunjukkan bahwa kepemimpinan transformasional memiliki pengaruh negatif terhadap kinerja, sedangkan variabel Kompetensi Keahlian memiliki pengaruh positif terhadap kinerja
\end{abstract}

Pedoman Sitasi: Hikmah, N. (2020). Kinerja Karyawan: Peran Transformasional Leadership Dan Skill Competence. SERAMBI: Jurnal E konomi M anajemen D an Bisnis I slam, 2(2), 131 - 142

D O I: https:/ / doi.org/ 10.36407/ serambi.v2i2.223
Received 05Aug 2020

Revised 20Aug 2020

A ccepted 22 Jun 2020

Online first 30 Aug 2020

\section{Paper type}

R esearch paper

$\triangle$ Email Korespondensi*: enha.najwa@gmail.com

Keywords: Performance, Transformational Leadership, Skill Competence, Employee Performance

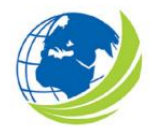

SERAMBI: Jurnal Ekonomi dan Bisnis Islam, Vol 2, N o.2, 2020,

pp. 131 - 142

elSSN 2685-9904 


\section{Pendahuluan}

Sumber daya manusia atau karyawan merupakan salah satu sumber daya yang penting dalam suatu perusahaan, dan sering disebut sebagai ujung tombak untuk mencapai tujuan perusahaan. Oleh karena itu, perusahaan memerlukan sumber daya manusia atau karyawan yang berkinerja tinggi sehingga dapat mencapai tujuan perusahaan yang telah ditetapkan. Salah satu unsur yang penting dalam upaya meningkakan kinerja karyawan adalah pemimpin yang mampu mempengaruhi bawahannya danmengikutsertakan bawahan secara aktif dalam mencapai tujuan tersebut melalui gaya kepemimpinan yang sesuai. Adanya keterkaitan atasan dan bawahan tersebut diharapkan dapat melahirkan suatu situasi yang harmonis sehingga menimbulkan kerjasama yang baik dalam mencapai tujuan perusahaan. Untuk itu organisasi memerlukan pemimpin yang reformis yang mampu menjadi motor penggerak perubahan (transformation) sehingga tercipta kerjasama yang baik antara pimpinan dan bawahan.

Salah satu gaya kepemimpinan yang menekankan pada pentingnya seorang pemimpin menciptakan visi dan lingkungan yang memotivasi para bawahan untuk berperestasi melampaui harapannya adalah kepemimpinan transformasional. Berbagai studi telah berhasil membuktikan bahwa kepemimpinan transformasi dapat meningkatkan kinerja pegawai Jiang, Zhao, \& Ni, 2017; Eliyana \& Ma'arif, 2019; Ritonga \& Ganyang, 2020; Katim \& Wiliyawati, 2016). Karena keterbukaan, kompleksitas, dan tantangan yang disajikan oleh banyak proyek, kepemimpinan transformasional dianjurkan (Bass, 1990). Kepemimpinan yang memiliki karakteristik seperti ini diyakini memiliki kompatibilitas bagi berbagai organisasi. Bass (1990) menjealskan bahwa kepemimpinan transformasional menginspirasi pengikut untuk menemukan cara baru untuk menghadapi tantangan dan memecahkan masalah. Meski demikian, dalam perkembangannya, kepemimpinan transformasional dianggap bukanlah preditor langsung kinerja, melainkan melalui beberapa perantara seperti kebermaknaan pekerjaan (Frieder, Wang \& Oh, 2018); kepuasan kerja (Prabowo, N oermijati, \& Irawanto, 2018); OCB (Jiang, Zhao, \& Ni, 2017); atau engagement (Buil, Martínez, \& Matute, 2019). Perbedaan model yang diuji ini menjadikan isu mengenai peran kepemimpinan transformasional pada kinerja karyawan secara langsung masih menarik untuk dieksplorasi.

Selain kepemimpinan, kinerja karyawan juga dibentuk dari kemampuan individu dari karyawan itu sendiri. Kemampuan individu atau kompetensi ini merupakan modal dasar seseorang untuk memberikan hasil maksimal pada kinerja. Organisasi akan berkembang dan mampu bertahan dalam lingkungan persaingan yang kompetitif apabila didukung oleh pegawai yang berkompeten di bidangnya. Pegawai merupakan asset organisasi yang vital karena memberi kontribusi besar sebagai penggerak roda organisasi. Kompetensi merupakan faktor yang mempengaruhi kinerja selain, kepemimpinan dan faktor lainnya. Berdasarkan uraian mengenai fenomena permasalahan tersebut di atas maka peneliti ingin melihat bagaimana pengaruh transformasional leadership dan skill competence terhadap kinerja karyawan PBMTI yang ada di wilayah jepara.

\section{Kajian Pustaka \\ Kinerja Karyawan}

Dari berbagai pengertian dapat disimpulkan kinerja merupakan hasil kerja baik itu secara kualitas maupun kuantitas yang telah dicapai oleh karyawan, dalam menjalankan tugastugasnya seusia dengan tanggungjawab yang diberikan organisasi, hasil kerja tersebut disesuaikan dengan yang diharapkan orgnaisasi mellaui kriteria atau standar yang berlaku dalam organisasi. berhasil tidaknya kinerja organisasi dipengaruhi oleh karyawan secara 
individual maupun kelompok. Terdapat 6 (enam) kriteria primer yang dapat digunakan untuk mengukur kinerja.

1. Q uality (Kualitas)

2. Quantity (Kuantitas)

3. Timeliness (ketepatan waktu)

4. Cost - Effectiviness ( efektivitas)

5. N eedForSupervision ( kemandirian)

6. Interpersonall mpact ( komitmen kerja)

\section{Kepemimpinan transformasional dan kinerja}

Kepemimpinan merupakan titik sentral dan penentu dari kegiatan yang akan dilaksanakan dalam organisasi. Kepemimpinan merupakan aktivitas untuk mempengaruhi orang lain agar supaya mereka mau diarahkan untuk mencapai tujuan tertentu. Kepemimpinan merupakan penggerak bagi sumber daya dan alat-alat yang dimiliki oleh perusahaan/ organisasi. Kepemimpinan bisa terjadi dimana saja, asalkan seseorang menunjukkan kemampuannya mempengaruhi perilaku orang lain ke arah tercapainya suatu tujuan tertentu. Siagian (2017) mengemukakan bahwa kepemimpinan adalah kemampuan seseorang untuk mempengaruhi orang lain (para bawahannya) sedemikian rupa sehingga orang lain mau melakukan kehendak pemimpin meskipun secara pribadi hal itu mungkin tidak disenanginya. Peran pemimpin dalam organisasi atau perusahaan ada tiga bentuk yaitu peranan yang bersifat interpersonal, peranan yang bersifat informasional dan peran pengambilan keputusan.

Pengaruh kepemimpinan transformasional terhadap kinerja pegawai dapat dijedaskan melalui perannya dalam memimpin bawahan. Pemimpin transformasional memiliki ciri khas menyampaikan kepada karyawan visi yang kuat tentang peluang pertumbuhan dalam tim mereka, mendorong karyawan untuk berpikir kritis tentang inisiatif perubahan, meningkatkan kepercayaan diri mereka untuk beradaptasi dengan berbagai perubahan, dan menekankan pentingnya kinerja sambil melampaui kepentingan pribadi demi tim (Bass, 1999). Karena gaya kepemimpinan seperti itu, karyawan kemudian lebih cenderung bereaksi secara positif untuk mengubah sikap dan perilaku. Misalnya, Herold, Fedor, Caldwell, dan Liu (2008) melaporkan hubungan positif antara kepemimpinan transformasional dan komitmen perubahan karyawan. Demikian pula, Detert dan Burris (2007) memberikan bukti bahwa kepemimpinan yang berorientasi pada perubahan (yaitu, transformasional) memprediksi kinerja pekerjaan di tingkat unit. Studi lebih baru melaporkan bahwa kepemimpinan transformasional secara lansung dapat mempengaruhi kinerja (misalnya Jiang, Zhao, \& Ni, 2017; Eliyana \& Ma'arif, 2019; Ritonga \& Ganyang, 2020; Katim \& Wiliyawati, 2016), atau secara tidak langsung melalui kebermaknaan pekerjaan (Frieder, Wang $\&$ Oh, 2018); kepuasan kerja (Prabowo, N oermijati, \& Irawanto, 2018); OCB (Jiang, Zhao, \& Ni, 2017); atau engagement (Buil, Martínez, \& Matute, 2019). Berdasarkan penjelasan tersebut maka hipotesis yang diajukan adalah:

$\mathrm{H}_{1}$ : kepemimpinan transformasional berpengaruh signifikan terhadap kinerja

\section{Kompetensi dan kinerja}

Spancer mengklasifikasikan dimensi dan komponen kompetensi individual menjadi tiga yaitu : pertama, kompetensi intelektual, adalah karakter sikap dan perilaku atau kemauan dan kemampuan intelektual individu (dapat berupa pengetahuan, ketrampilan, pemahaman 
professional, pemahaman kontekstual) yang bersifat realatif stabil ketika menghadapi permasalahan ditempat kerja yang dibentuk dari sinergi antara watak, konsep diri, motivasi internal serta kapasitas pengetahuan kontekstual. Kompetensi intelektual ini terinternalisasi dalam bentuk Sembilan kompetensi yaitu: berprestasi, kepastian kerja , inisiatif, penguasaan informasi, berpikir analitik, berpikir konseptual, keahlian praktikal, kemampuan linguistic, dan kemampuan naratif

Kedua, kompetensi emosional. Adalah karakter sikap dan perilaku atau kemauan dan kemampuan untuk menguasai diri dan memahami lingkungan secara obyektif dan moralis sehingga pola emosinya real atif stabil ketika menghadapi berbagai permasalahan di tempat kerja yang terbentuk melalui sinergi antara watak, konsep diri, motivasi internal serta kapasitas pengetahuan mental/ emosional. Kompetensi emosional individu terinternalisasi dalam bentuk enam tingkat kemauan dan kemampuan sebgai beikut : sensitifitas atau saling pengertian, kepedulian, pengendalian diri, percaya diri, kemampuan beradaptasi, komitmen pada organisasi.

Ketiga, kompetensi social, adalah karakter sikap dan perilaku atau kemauan dan kemampuan untuk membangun simpul-simpul kerjasama dengan orang lain yang realtif bersifat stabil ketika menghadapi permasalhan di tempat kerja yang berbentuk sinergi antara watak, konsep diri, motivasi internal serta kapsitas pengethuan social. Kompetensi sosial terinternalisasi dalam tujuh tingkat kemauan dan kemampuan sebagai berikut: pengaruh dan dampak, kesadaran, berorganisasi, membangun hubungan kerja, mengembangkan orang lain, mengarahkan, bawahan, kerja tim, dan kepemimpinan kelompok

Kompetensi berpengaruh terhadap kinerja karyawan. Semakin tinggi kompetensi yang dimiliki oleh karyawan dan sesuai dengan tuntutan peran pekerjaan maka kinerja karyawan akan semakin meningkat. Karyawan yang kompeten biasanya memiliki karaker dan sikap serta perilaku juga kemauan kerja yang stabil ketika menghadapi suatu situasi ditempat kerja, yang terbentuk dari sinergi antara karakteristik dalam kompetensi yaitu watak, kosnep diri, motivasi internal dan kapasitas pengetahuan kontekstualnya sehingga ia dengan cepat dapat mengatasi permasalahan kerja yang dihadapi, melakukan pekerjaan dengan tenang dan penuh dengan rasa percaya diri , memandang pekerjaan sebagai suatu kewajiban yang harus dilakukan secara ikhlas, dan secara terbuka meningkatkan kualitas diri melalui proses pembelajaran.

Sejak beberapa dekade terakhir, kompetensi sering digunakan sebagai dasar penilaian kinerja dan atau digunakan sebagai alat ukur untuk mengidentifikasi faktor-faktor perilaku yang relevan dengan bidang kerja terntu dan bagaimana pekerjaan tersebut dijalankan (Cardy dan Selvarajan, 2006). Oleh karena itu, tak mengherankan jika banyak organisasi menggunakan model kompetensi sebagai bagian dari program pengembangan karyawan mereka untuk menilai indikator kinerja perilaku bersama-sama dengan tujuan (Özçelik dan Ferman, 2006). Sejalan dengan itu, banyak ahli (Levenson, et.al, 2006, Ryan, et.al., 2009) telah menyatakan bahwa penilaian kompetensi karyawan memberikan metode yang efektif untuk memprediksi kinerja pekerjaan. Terdapat banyak penelitian yang menunjukkan pengaruh kompetensi tertentu terhadap prestasi kerja individu. Misalnya Qiao dan Wang, (2009) menyarankan bahwa kompetensi pengembangan tim, komunikasi efektif; koordinasi, pelaksanaan dan pembelajaran berkelanjutan merupakan indkator terpenting untuk keberhasilan manajer. Demikian pula, terdapat bukti empiris yang menunjukkan hubungan antara kompetensi seperti Zaim, Yaşar \& Ünal (2013) yang mengungkapkan bahwa terdapat hubungan positif antara kompetensi dengan kinerja individu. Selain itu, kompetensi inti tampaknya memiliki pengaruh paling signifikan terhadap kinerja individu. Hasil penelitian ini memberikan beberapa bukti empiris yang 
mengacu pada pengaruh kompetensi individu terhadap kinerja organisasi. Berdasarkan uraian di atas maka hipotesis yang diajukan adalah:

$\mathrm{H}_{2}$ : kompetensi berpengaruh signifikan terhadap kinerja

\section{M etode Penelitian}

Jenis data yang diperlukan dalam penelitian ini adalah data primer. Yaitu data yang berasal langsung dari sumber data yang dikumpulkan secara khusus dan berhubungan langsung dengan masalah penelitian yang akan diteliti. Sumber data dalam penelitian ini didapat dari penyebaran angket yang berisi kuesioner. Populasi dalam penelitian ini adalah seluruh karyawan BMT di Jepara yang masuk dalam perhimpunan BMT Indonesia wilayah daerah jepara . yang berjumlah 392 karyawan yang terdiri dari General manager, Manager, Kepala cabang, kepala bagian pembiayaan, accounting, marketing, teller. Metode pengambilan sampel yang akan digunakan dalam penelitian ini yaitu dengan menggunakan Disproportionate Stratified Sampling. Yaitu merupakan cara pengambilan sampel melalui keputusan berdasarkan ide bahwa setiap strata. Jumlah sampel yang digunakan dalam penelitian ini adalah sebanyak 100 orang. Penentuan jumlah responden yang akan dijadikan sampel penelitian menggunakan formulasi Slovin.

Angket yang akan digunakan dalam penelitian ini merupakan angket langsung dan tertutup, artinya angket tersebut langsung diberikan kepada responden dan responden diharuskan memilih jawaban yang telah tersedia. Metode angket tersebut menggunakan penilaian atas kuesioner dengan menggunakan skala penilaian antara 1-5. Penelitian ini menggunakan tehnik Partial least Square. dengan menggunakan software smart PLS V.4.0.untuk mengukur empat konstruk yang terdapat dal am pengujian model, peneliti menggunakan 60 item pertanyaan. 12 item pertanyaan untuk mengukur tranformasional leadership, 15 item pertanyaan untuk mengukur skillcompetence, dan 15 pertanyaan untuk mengukur kinerja karyawan.

\section{Hasil dan Diskusi \\ Evaluasi Validitas Konstruk}

Suatu instrument dikatakan memenuhi pengujian validitas konvergen apabila memiliki loading factor diatas 0.6. Hasil pengujian validitas konvergen disajikan dalam tabel berikut :

Berdasarkan tabel di atas dapat diketahui bahwa semua indicator yang mengukur variabel Transformasional Leadership, Skill Competence, dan kinerja karyawan PBMTI yang ada di wilayah jepara bernilai lebih besar dari 0.6. Dengan demikian indikator tersebut dinyatakan valid untuk mengukur variabelnya. Validitas konvergen juga dapat diketahui melalui Average $V$ ariance Extracted (AVE) dan Communality. Suatu instrument dikatakan memenuhi pengujian validitas konvergen apabila memiliki A verage $V$ ariance Extracted (AVE) dan Communality diatas 0.5 (Hair et al., 2016). Hasil pengujian validitas konvergen disajikan dalam tabel 1.

Tabel 2 merupakan pengujian reliabilitas. Seperti yang ditampilkan pada Tabe 2 dapat diketahui bahwa semua variabel, menghasilkan nilai Average Variance Extracted (AVE) dan Communalityyang lebih besar dari 0.5. Dengan demikian indikator tersebut dinyatakan valid untuk mengukur variabelnya. Selanjutnya validitas diskriminan dihitung menggunakan cross correlation dengan kriteria bahwa apabila nilai loading factor dalam suatu variabel yang bersesuaian lebih besar dari nilai korelasi indikator pada variabel lainnya maka indikator tersebut dinyatakan valid dal am mengukur variabel yang bersesuaian. 
SERAMBI: Jurnal Ekonomi Manajemen dan Bisnis Islam

Tabel 1. Validitas Konvergen dengan Loading Factor

\begin{tabular}{lll}
\hline Variabel & Indikator & 0 riginal Sample (0) \\
\hline & X1.1 & 0,796 \\
Transformasional Leadership & X1.2 & 0,768 \\
& X1.3 & 0,817 \\
X1.4 & 0,899 \\
\hline Xkill Competence & X2.1 & 0,873 \\
& X2.3 & 0,823 \\
& X2.4 & 0,842 \\
& X2.5 & 0,844 \\
kinerja karyawan & Y2 & 0,813 \\
\hline & Y3 & 0,768 \\
Y4 & 0,881 \\
Y5 & 0,909 \\
\hline
\end{tabular}

Sumber: diolah dengan SMART PLS

Tabel 3. Validitas konvergen dengan AVE dan Communality

\begin{tabular}{lll}
\hline Variabel & AVE & Communality \\
\hline Transformasional Leadership & 0,675 & 0,675 \\
Skill Competence & 0,705 & 0,705 \\
kinerja karyawan & 0,713 & 0,713 \\
\hline
\end{tabular}

Sumber: diolah dengan SMART PLS

Tabel 3. Validitas diskriminan dengan CrossC orrelation

\begin{tabular}{llll}
\hline Indikator & $\begin{array}{l}\text { Transformasional } \\
\text { Leadership }\end{array}$ & Skill Competence & $\begin{array}{l}\text { Kinerja } \\
\text { karyawan }\end{array}$ \\
\hline X1.1 & $\mathbf{0 , 7 9 6}$ & 0,522 & 0,435 \\
X1.2 & $\mathbf{0 , 7 6 8}$ & 0,589 & 0,530 \\
X1.3 & $\mathbf{0 , 8 1 7}$ & 0,518 & 0,509 \\
X1.4 & $\mathbf{0 , 8 9 9}$ & 0,680 & 0,597 \\
\hline X2.1 & 0,612 & $\mathbf{0 , 8 7 3}$ & 0,708 \\
X2.2 & 0,495 & $\mathbf{0 , 8 2 4}$ & 0,619 \\
X2.3 & 0,496 & $\mathbf{0 , 8 4 1}$ & 0,659 \\
X2.4 & 0,698 & $\mathbf{0 , 8 4 4}$ & 0,736 \\
X2.5 & 0,649 & $\mathbf{0 , 8 1 3}$ & 0,734 \\
\hline Y1 & 0,552 & 0,617 & $\mathbf{0 , 7 6 8}$ \\
Y2 & 0,547 & 0,729 & $\mathbf{0 , 8 8 1}$ \\
Y3 & 0,561 & 0,774 & $\mathbf{0 , 9 0 8}$ \\
Y4 & 0,586 & 0,728 & $\mathbf{0 , 8 1 4}$ \\
Y5 & 0,443 & 0,634 & $\mathbf{0 , 8 4 3}$ \\
\hline
\end{tabular}

Sumber: diolah dengan SMART PLS 
Berdasarkan pengukuran cross correlation pada tabel di atas, dapat diketahui bahwa secara keseluruhan indikator-indikator dari variabel Transformasional Leadership, Skill Competence, dan kinerja karyawan PBMTI yang ada di wilayah jepara menghasilkan loading factor yang lebih besar dibandingkan dengan cross correlation pada variabel lainnya. Dengan demikian dapat dinyatakan bahwa masing-masing indikator mampu mengukur variabel laten yang bersesuaian dengan indikatornya.

\section{Hasil Evaluasi Reliabilitas}

Perhitungan yang dapat digunakan untuk menguji reliabilitas konstruk adalah Cronbach Alpha dan Composite Reliability. Kriteria pengujian menyatakan bahwa apabila Composite Reliability bernilai lebih besar dari 0.7 dan cronbach alpha bernilai lebih besar dari 0.6 maka konstruk tersebut dinyatakan reliabel.

Tabel 4. Reliabilitas dengan CronbachAIpha dan Composite relaibility

\begin{tabular}{lll}
\hline Variabel & CompositeR eliability & CronbachsAlpha \\
\hline Transformasional Leadership & 0,892 & 0,839 \\
Skill Competence & 0,923 & 0,895 \\
kinerja karyawan & 0,925 & 0,898 \\
\hline
\end{tabular}

Sumber: diolah dengan SMART PLS

Berdasarkan tabel di atas dapat diketahui bahwa nilai composite reliability pada variabel Transformasional Leadershipsebesar 0.892, variabel Skill Competencesebesar 0.923, dan kinerja karyawan PBMTI sebesar 0.925. Hasil tersebut menunjukkan nilai composite reliability yang lebih besar dari 0.7. Dengan demikian, berdasarkan perhitungan composite reliability semua indikator dinyatakan reliabel dalam mengukur variabel latennya.

Selanjutnya nilai Cronbach's Alpha pada variabel Transformasional Leadershipsebesar 0.839, variabel Skill Competencesebesar 0.895, dan kinerja karyawan PBMTI sebesar 0.898. Hasil tersebut menunjukkan semua variabel menghasilkan nilai Cronbach's Alpha yang lebih besar dari 0.6. Dengan demikian, berdasarkan perhitungan Cronbach's Alpha semua indikator yang mengukur variabel Transformasional Leadership, Skill Competence; dan dan kinerja karyawan PBMTI dinyatakan reliabel dalam mengukur variabel latennya.

\section{GoodnessofFitModel}

Goodness of fit M odel digunakan untuk mengetahui besarnya kemampuan variabel endogen untuk menjelaskan keragaman variabel eksogen, atau dengan kata lain untuk mengetahui besarnya kontribusi variabel eksogen terhadap variabel endogen. Goodness of fit Model dalam analisis PLS dilakukan dengan menggunakan Q-Square predictive relevance ( $\left.Q^{2}\right)$.Namun apabila variabel dependen hanya satu, maka digunakan koefisien determinasi $\mathbf{R}^{2}$. Adapaun hasil Goodness of fit Model yang telah diringkas dalam tabel berikut. R-square variabel kinerja karyawan bernilai 0.792 atau $79.2 \%$. Hal ini dapat menunjukkan bahwa keragaman variabel kinerja karyawan PBMTI mampu dijelaskan oleh variabel Transformasional Leadership, Skill Competence; dan sebesar $79.2 \%$, atau dengan kata lain kontribusi variabel Transformasional Leadership, Skill Competence; terhadap kinerja karyawan PBMTI sebesar 79.2\%, sedangkan sisanya sebesar $20.8 \%$ merupakan kontribusi variabel lain yang tidak dibahas dalam penelitian ini. 


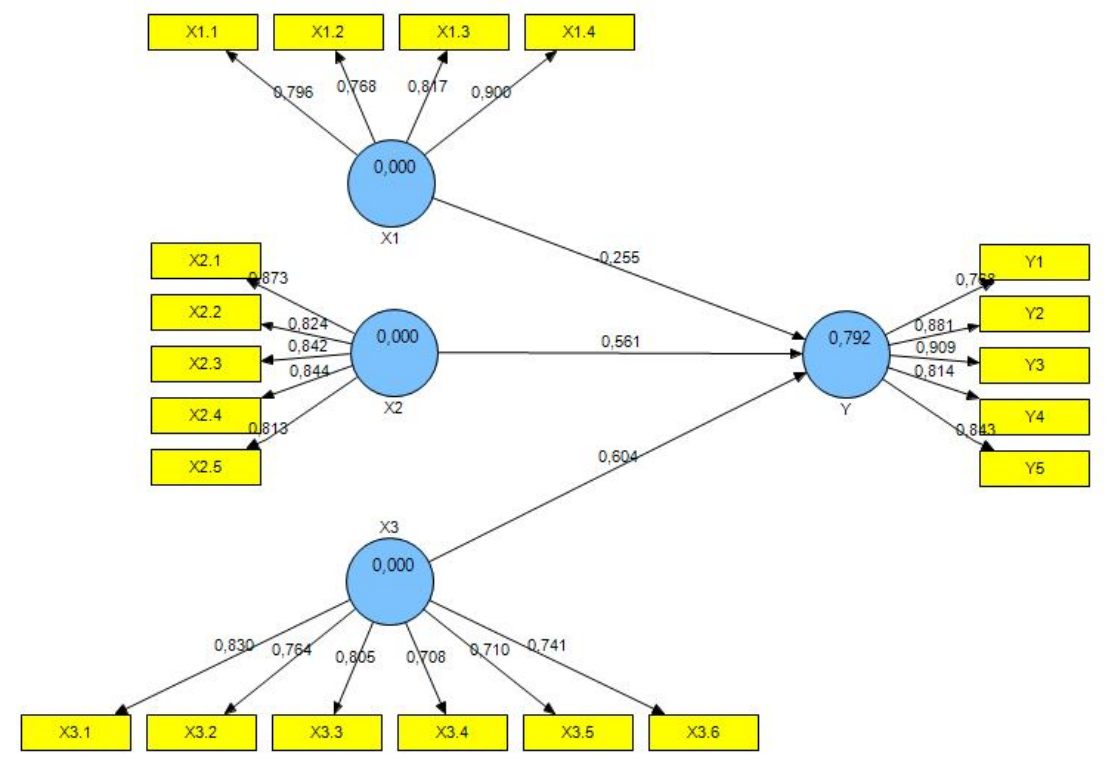

Gambar 2 M odel Struktural

\section{Pengujian Hipotesis}

Pengujian signifikansi digunakan untuk menguji ada tidaknya pengaruh variabel eksogen terhadap variabel endogen. Kriteria pengujian menyatakan bahwa apabila nilai T-statistics $\geq \mathrm{T}$ tabel (1.96) maka dinyatakan adanya pengaruh signifikan variabel eksogen terhadap variabel endogen. hasil pengujian signifikansi dapat diketahui melalui tabel berikut.

\section{Tabel 5. Nilai hasil Koefisien dan T -Statisttic}

\begin{tabular}{llll}
\hline Variabel Eksogen & $\begin{array}{l}\text { Variabel } \\
\text { Endogen }\end{array}$ & $\begin{array}{l}\text { Original } \\
\text { Sample (O) }\end{array}$ & $\begin{array}{l}\text { T Statistics } \\
(\mid \text { O/ STERR| ) }\end{array}$ \\
\hline Transformasional Leadership & $\begin{array}{l}\text { kinerja } \\
\text { karyawan } \\
\text { kinerja } \\
\text { karyawan }\end{array}$ & $-0,255$ & 3,092 \\
Skill Competence & 0,561 & 7,977 \\
\hline
\end{tabular}

\section{Sumber: diolah dengan SMART PLS}

Hipotesis 1 yaitu pengaruh Transformasional Leadershipterhadap kinerja karyawan. Hasil pengujian tersebut menunjukkan bahwa nilai T statistics $>1$.96. Hal ini berarti terdapat pengaruh yang signifikan Transformasional Leadershipterhadap kinerja karyawan. Hipotesis 2 yaitu pengaruh Skill Competenceterhadap kinerja karyawan. Hasil pengujian tersebut menunjukkan bahwa nilai $\mathrm{T}$ statistics $>1$ 1.96. Hal ini berarti terdapat pengaruh yang signifikan Skill Competenceterhadap kinerja karyawan.

\section{Konversi D iagram Jalur ke dalam M odel Struktural}

Dari diagram jalur dan tabel 4.14 di atas dapat dibuat persamaan sebagai berikut

$$
\begin{array}{ll}
\mathrm{Y} & =\beta \mathrm{X} 1+\beta \mathrm{X} 2+\beta \mathrm{X} 3+\mathrm{e} \\
\mathrm{Y} & =-0.255 \mathrm{X} 1+0.561 \times 2+\mathrm{e}
\end{array}
$$


Dari persamaan dapat diinformasikan bahwa Koefisien direct effect Transformasional Leadershipterhadap kinerja karyawan sebesar -0.255 menyatakan bahwa Transformasional Leadershipberpengaruh negatif dan signifikan terhadap kinerja karyawan. Hal ini berarti semakin tinggi Transformasional Leadershipmaka cenderung dapat menurunkankinerja karyawan. Koefisien D irecteffectSkill Competence sebesar 0.561 menyatakan bahwa Skill Competenceberpengaruh positif dan signifikan terhadap kinerja karyawan. Hal ini berarti semakin tinggi Skill Competencemaka cenderung dapat meningkatkan kinerja karyawan.

\section{Pembahasan Hasil A nalisis}

Berdasarkan Hasil pengujian dapat disimpulkan bahwa Transformasional Leadership berpengaruh signifikan terhadap kinerja karyawan PBMTI Jepara. Hal ini dapat dilihat dari nilai T- statistic yang lebih besar dari 1,96 yaitu sebesar 3.093. Tetapi Transformasional Leadership ternyata berpengaruh negatif terhadap kinerja karyawan PBMTI Jepara, Jadi semakin tinggi pola kepemimpinan transformasional diterapkan, maka justru menurunkan kinerja karyawan. Hal ini menunjukkan hipotesis 1 ditolak. Penurunan karyawan terjadi karena faktor gap pengetahuan antar level karyawan, perbedaan pengetahuan, Pendidikan antar sesama karyawan, tunjangan/ gaji, kemampuan potensi (IQ), kemampuan mengelola emosional (EQ), fasilitas kerja, yang akan mempengaruhi penerapan pola kepemimpinan. Hasil penelitian ini tidak sejalan dengan teori Bass yang menyatakan kepemi mpinan transformasional lebih meningkatkan kinerja karyawan. Hasil penelitian ini tidak mendukung studi sebelumnya (misalnya Jiang, Zhao, \& Ni, 2017; Eliyana \& Ma’arif, 2019; Ritonga \& Ganyang, 2020; Katim \& Wiliyawati, 2016).

Berdasarkan hasil perhitungan dengan analisis PLS diketahui bahwa skill competence berpengaruh signifikan dan positif terhadap kinerja karyawan. Hal ini dapat dilihat dari nilai tstatistic yang lebih besar dari 1,96 yaitu sebesar 7.978. Dalam hal pengaruh dapat dilihat pada nilai koefisien direct effect sebesar 0.561 yang berarti skill competence memiliki pengaruh positif terhadap kinerja karyawan PBMTI Jepara . Hal ini berarti Hipotesis 2 terdukung. Hasil penelitian ini sejalan dengan pemahaman dalam kajian teori Mangkunegara yang mendukung bahwa kompetensi mempengaruhi kinerja karyawan dan salah satu faktor yang mempengaruhi kinerja seseorang yaitu kemampuan yang terdiri dari kemampuan potensi dan kemampuan realitas ( knowledge dan skill). Temuan ini mendukung asumsi bahwa kompetensi merupakan faktor penting yang mempengaruhi kinerja (Cardy dan Selvarajan, 2006). Qiao dan Wang, (2009) menyarankan bahwa kompetensi pengembangan tim, komunikasi efektif; koordinasi, pelaksanaan dan pembelajaran berkelanjutan merupakan indkator terpenting untuk keberhasilan manajer. Demikian pula, terdapat bukti empiris yang menunjukkan hubungan antara kompetensi seperti Zaim, Yaşar \& Ünal (2013) yang mengungkapkan bahwa terdapat hubungan positif antara kompetensi dengan kinerja individu. Hasil penelitian ini memberikan beberapa bukti empiris yang mengacu pada pengaruh kompetensi individu terhadap kinerja organisasi.

\section{Kesimpulan}

Secara umum penelitian bertujuan untuk menguji pengaruh kepemimpinan transformasional dan kompetensi terhadap kinerja karyawan. Berdasarkan hasil analisis diperoleh kesimpulan bahwa studi ini hanya berhasil mendukung pengaruh signifikan kompetensi terhadap, sedangkan kepemimpinan transformasional tidak berhasil dibuktikan. Implikasi dari temuan ini adalah upaya untuk meningkatkan kinerja karyawan dapat didorong melalui peningkatkan kompetensi karyawan. Hal ini dapat dilakukan melalui pelatihan-pelatihan yang dapat diprogramkan secara berkala sesuai dengan kebutuhan skill di lapangan. 
Beberapa keterbatasan yang masih ada dalam studi ini antara lain: pertama, sampel yang digunakan dalam studi merupakan sampel yang berada dalam satu perusahaan sehingga generalisasi hasil untuk perusahaan lain yang lebih besar perlu dilakukan secara hati-hati. Kedua, pengambilan data dalam studi ini menggunakan desain cross-sectional sehingga memiliki kelemahan dalam menjelaskan kausalitas hubungan antar variabel. Berdasarkan keterbatasan tersebut maka saran yang diajukan untuk riset mendatang adalah perlu dilakukan studi yang mengikutsertakan sampel yang lebih besar dan tersebar di beberapa perusahaan. Selain itu, penggunaan desain longitudinal dapat menjadi alternative untuk menguji hubungan sebab akibat antar variabel.

\section{Daftar Pustaka}

Amboningtyas, D. (2019). Transformasi Human Resources Sebagai Strategic Business Partner (Studi Kasus pada UMKM Kota Semarang).Jurnal Ekbis: Analisis, Prediksi Dan Informasi, 20(2), 1290-1297.

Bass, B. M. (1990). From transactional to transformational leadership: Learning to share the vision. Organizational dynamics, 18(3), 19-31.

Buil, I., Martínez, E., \& Matute, J. (2019). Transformational leadership and employee performance: The role of identification, engagement and proactive personality. International Journal of $\mathrm{H}$ ospital ity $\mathrm{M}$ anagement, 77, 64-75.

Detert, J. R., \& Burris, E. R. (2007). Leadership behavior and employee voice: Is the door really open?A cademy of ManagementJ ournal,50, 869-884.

Eliyana, A., \& Ma'arif, S. (2019). Job satisfaction and organizational commitment effect in the transformational leadership towards employee performance. European Research on $M$ anagement and Business Economics, 25(3), 144-150.

Ferdinand, A. (2005), Structural Equation M odelling Dalam Penelitian M anajemen,Badan Penerbit UNDIP, Semarang.

Frieder, R. E., Wang, G., \& Oh, I.-S. (2018). Linking job-relevant personality traits, transformational leadership, and job performance via perceived meaningfulness at work: A moderated mediation model. Journal of Applied Psychology, 103(3), 324-333. https:/ / doi.org/ 10.1037/ apl0000274

Hair Jr, J. F., Hult, G. T. M., Ringle, C., \& Sarstedt, M. (2016). A primer on partial least squares structural equation modeling (PLS-SEM). Sage publications.

Herold, D. M., Fedor, D. B., Caldwell, S. D., \& Liu, Y. (2008). The effects of transformational leadership and change leadershipon employees'commitment to a change: A multileve study.J ournal of A pplied Psychology,93, 346-357

Jiang, W., Zhao, X., \& Ni, J. (2017). The impact of transformational leadership on employee sustainable performance: The mediating role of organizational citizenship behavior. Sustainability, 9(9), 1567.

Katim, K., \& Wiliyawati, C. (2016). Pengaruh Gaya Kepemimpinan Transaksional dan Motivasi terhadap Kinerja Karyawan (Studi pada Merlynn Park Hotel di Jakarta Pusat). Jurnal Riset M anajemen dan Bisnis (JRM B) Fakultas Ekonomi U NIA T, 1(2), 177-182.

Levenson, A. R., Van der Stede, W. A., \& Cohen, S. G. (2009). Measuring the Relationship Between Managerial Competencies and Performance. Journal of Management, 32(3), 360380.

Ozcelik, G., \& Ferman, M. (2006). Competency Approach to Human Resources Management:Outcomes and Contributions in a Turkish Cultural Context. Human Resource Development Review, 5(1), 72-9

Prabowo, T. S., N oermijati, N., \& Irawanto, D. W. (2018). The influence of transformational leadership and work motivation on employee performance mediated by job satisfaction. Jurnal A plikasi M anajemen, 16(1), 171-178. 
SERAMBI, 2(2), 131 - 142

N ur Hikmah. Transformational leadership, competencies, employee performance...

Qiao, J. X., \& Wang, W. (2009). Managerial competencies for middle managers: some empirical findings from China. Journal of European Industrial Training, 33(1), 69-80

Ryan, G., Emmerling, R. J., \& Spencer, L. M. (2009). Distinguishing high-performing European executives. Journal of Management Development, 28(9), 859-875.

Ritonga, W., \& Ganyang, M. T. (2020). Kinerja Karyawan: Peran Gaya Kepemimpinan Dan Kepuasan Kerja. Jurnal Riset Manajemen dan Bisnis (JRM B) Fakultas Ekonomi U NIAT, 5(1), 289-298.

Siagian, S. P. (2017). Manajemen sumber daya manusia. Bumi Aksara.

Sopiah (2008). Perilaku Organisasional, Yogjakarta: Andi

Zaim, H., Yaşar, M. F., \& Ünal, Ö. F. (2013). Analyzing the effects of individual competencies on performance: A field study in services industries in Turkey. Journal of Global Strategic $M$ anagement, 7(2), 67-77. 
SERAMBI: Jurnal Ekonomi Manajemen dan Bisnis Islam Published by LPMP Imperium

\section{A bout Authors}

Nur Hikmah adalah dosen di Program Studi Administrasi Bisnis Internasional, Politeknik Balekambang. penulis memiliki ketertarikan di bidang manajemen sumber daya manusia, kepemimpinan, dan pengembangan SDM. Penulis dapat dihubungi di email: enha.najwa@gmail.com

Accepted author version posted online: 30 Agustus 2020

$$
\text { (c) (i) }
$$

(C) 2020 The Author(s). This open access article is distributed under a CreativeCommons Attribution (CC-BY) 4.0 license 